Check for updates

Cite this: J. Mater. Chem. A, 2022, 10 3233

DOI: $10.1039 / \mathrm{d} 1 \mathrm{ta} 90271 \mathrm{~g}$

rsc.li/materials-a

\section{Correction: Light-driven carbon dioxide reduction coupled with conversion of acetylenic group to ketone by a functional Janus catalyst based on keplerate $\left\{\mathrm{Mo}_{132}\right\}$}

\author{
Joyeeta Lodh, ${ }^{\mathrm{ab}}$ Apabrita Mallick ${ }^{\mathrm{ab}}$ and Soumyajit Roy*ab
}

Correction for 'Light-driven carbon dioxide reduction coupled with conversion of acetylenic group to ketone by a functional Janus catalyst based on keplerate $\left\{\mathrm{Mo}_{132}\right\}$ ' by Joyeeta Lodh et al., J. Mater. Chem. A, 2018, 6, 20844-20851, DOI: 10.1039/C8TA06243A.

There is an error in Fig. 7(a) of the published article, whereby incorrect Raman spectra were presented. The corrected Fig 7(a) is shown below. This replacement does not affect the conclusions of the published paper. It is to be noted that concerns were raised as the figure refers to the same catalyst, and is similar, to the Raman spectrum of the same catalyst published in earlier papers by these authors. However, the published figures represent different data sets, each of which were obtained from distinct experiments performed independently and under distinctly different conditions. The journal editorial office consulted an independent reviewer who reviewed the raw data sets and confirmed that the authors had provided separate data sets for each experiment.

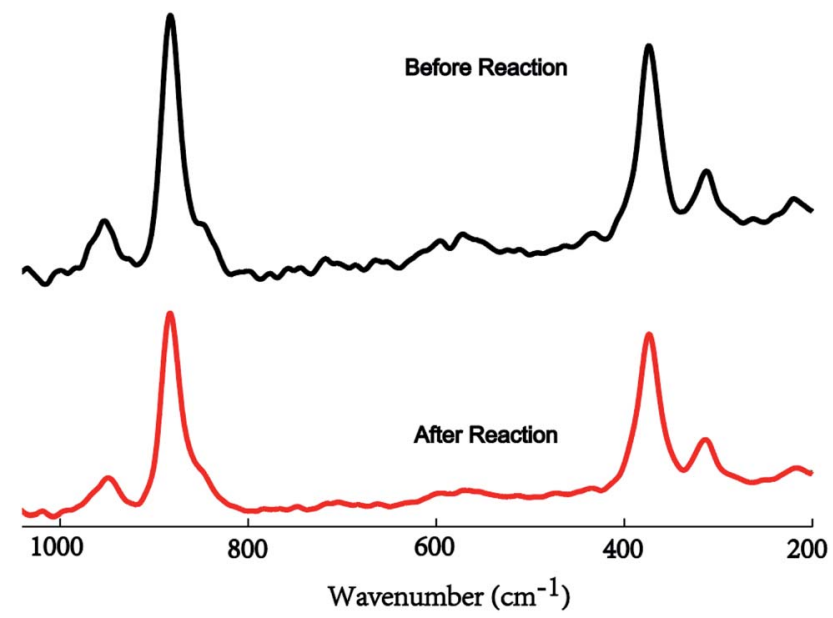

Fig. 7(a) Raman spectra of $\left\{\mathrm{Mo}_{132}\right\}$ before and after reaction showing identical peaks.

The Royal Society of Chemistry apologises for these errors and any consequent inconvenience to authors and readers. 